\title{
Evolução das redes profissionais de agricultores e formas de assessoria em agricultura biológica: quais os desafios para o desenvolvimento? \\ O caso da Bretanha*
}

\section{The evolution of farmers' professional networks and council forms in biological agriculture: challenges for development. The case of Brittany}

\author{
Claire RUAULT**
}

\section{RESUMO}

O importante desenvolvimento que conhece atualmente a agricultura biológica tem por conseqüência uma recomposição das redes de relações profissionais dos agricultores ligada à chegada de "novos" agricultores biológicos e ao aumento do crédito acordado a esse modo de produção no interior dos organismos profissionais agrícolas; além de uma evolução da posição ocupada pela agricultura biológica no campo do desenvolvimento agrícola, marcada pelo aumento da oferta de assessoria aos agricultores bios. Trata-se de mostrar, através do estudo das redes de relações profissionais em diversas sub-regiões (départements) ${ }^{1}$ do oeste da França, o que caracteriza hoje as formas de organização social do trabalho na agricultura biológica e de interrogar seu papel em torno de duas questões: o modo com o qual os agricultores tomam parte (ou tentam guardar uma certa autonomia) na evolução das formas de produção e de introdução de seus produtos no mercado e o modo como são geridas as diversas "maneiras de exercer a profissão de agricultor" que caracterizam a agricultura biológica e as condições segundo as quais ela pode ser mantida. A ênfase é colocada sobre a importância do multipertencimento dos agricultores bios e sobre o papel complementar que têm as diferentes redes (rede local de vizinhança, redes microrregionais ou departamentais específicas aos agricultores bios) como suporte de elaboração de conhecimentos e de tratamento de questões que se põem concretamente aos agricultores frente às mudanças em curso. Tomando como base o desenvolvimento agrícola em plena estruturação, é em torno destas mesmas questões que procura-se interrogar, paralelamente e de maneira prospectiva, as práticas de assessoria e as maneiras de apoiar aos agricultores bios, tendo em vista o surgimento de novos desafios na distribuição das funções e dos papéis dos agentes entre os diferentes organismos.

Palavras-chave: redes de profissionais, agricultura biológica.

* Tradução: Eduardo Britto Santos e Alfio Brandenburg

* Socióloga do Groupe d'Expérimentation et de Recherche, Développement et Actions Localisées - Gerdal. Contato: C. RUAULT, Gerdal Ouest: La Houdinais, 35160. Le Verger: 0299079868.

1 Os départements fazem parte das regiōes administrativas na política administrativa da República Francesa. (NT) 


\title{
Evolução das redes profissionais de agricultores e formas de assessoria em agricultura biológica: quais os desafios para o desenvolvimento? \\ O caso da Bretanha*
}

\section{The evolution of farmers' professional networks and council forms in biological agriculture: challenges for development. The case of Brittany}

\author{
Claire RUAULT ${ }^{* *}$
}

\begin{abstract}
RESUMO
O importante desenvolvimento que conhece atualmente a agricultura biológica tem por consequiência uma recomposição das redes de relações profissionais dos agricultores ligada à chegada de "novos" agricultores biológicos e ao aumento do crédito acordado a esse modo de produção no interior dos organismos profissionais agrícolas; além de uma evolução da posição ocupada pela agricultura biológica no campo do desenvolvimento agrícola, marcada pelo aumento da oferta de assessoria aos agricultores bios. Trata-se de mostrar, através do estudo das redes de relações profissionais em diversas sub-regiões (départements) ${ }^{1}$ do oeste da França, o que caracteriza hoje as formas de organização social do trabalho na agricultura biológica e de interrogar seu papel em tomo de duas questões: o modo com o qual os agricultores tomam parte (ou tentam guardar uma certa autonomia) na evolução das formas de produção e de introdução de seus produtos no mercado e o modo como são geridas as diversas "maneiras de exercer a profissão de agricultor" que caracterizam a agricultura biológica e as condições segundo as quais ela pode ser mantida. A ênfase é colocada sobre a importância do multipertencimento dos agricultores bios e sobre o papel complementar que têm as diferentes redes (rede local de vizinhança, redes microrregionais ou departamentais específicas aos agricultores bios) como suporte de elaboração de conhecimentos e de tratamento de questões que se põem concretamente aos agricultores frente às mudanças em curso. Tomando como base o desenvolvimento agrícola em plena estruturação, é em torno destas mesmas questões que procura-se interrogar, paralelamente e de maneira prospectiva, as práticas de assessoria e as maneiras de apoiar aos agricultores bios, tendo em vista o surgimento de novos desafios na distribuição das funções e dos papéis dos agentes entre os diferentes organismos.
\end{abstract}

Palavras-chave: redes de profissionais, agricultura biológica.

* Tradução: Eduardo Britto Santos e Alfio Brandenburg

** Socióloga do Groupe d'Expérimentation et de Recherche, Développement et Actions Localisées - Gerdal. Contato: C. RUAULT, Gerdal Ouest: La Houdinais, 35160. Le Verger: 0299079868 .

1 Os départements fazem parte das regiões administrativas na política administrativa da República Francesa. (NT) 
Temos então o direito de nos perguntarmos como é gerada a diversidade de maneiras de produzir e de concepções que caracterizam hoje a agricultura biológica. Essa diversidade conseguirá se manter, ou não arriscamos ir em direção ao processo de seleção ligado ao fato de que uma certa forma de produção está em vias de tornar-se "um novo modelo" de excelência técnica?

Podemos igualmente nos interrogar sobre os efeitos do desenvolvimento da agricultura biológica quanto à capacidade dos atores do mundo agrícola - e dos agricultores bios em particular - em conservar uma certa autonomia e uma certa iniciativa no que concerne à evolução das formas de produção e de introdução de seus produtos no mercado.

É sobre estas questões que está fundamentada a reflexão a que nos propomos aqui. Para tratá-las, procederemos em dois tempos. Numa primeira parte, nos esforçaremos em mostrar o que podemos dizer a partir do exame das características das redes de relações profissionais nas quais se inscreve atualmente o exercício da agricultura biológica. A atenção particular dada a essas redes se justifica pelo fato de que elas se constituem, conforme pensamos, em um lugar de elaboração da qualificação profissional dos agricultores. Sua descrição (como elas são constituídas e como evoluem) fornece uma via de acesso privilegiada para compreender o modo pelo qual os agricultores buscam resolver os problemas que estão postos diante das mudanças em curso. Nos apoiaremos, para isso, em estudos desenvolvidos em diversas sub-regiões da Bretanha e da região do Loire. Numa segunda parte, examinaremos, a partir do exemplo da Bretanha, a maneira como se organiza a assessoria dos agricultores bios e com a qual eles se integram às concepções usuais dos agentes de desenvolvimento agrícola, que compreendemos como "práticos" do desenvolvimento (DE SARDAN, 1995). Procuraremos ver quais ensinamentos podemos obter ao observar essas questões, privilegiando uma abordagem em termos das interações relacionadas às perspectivas dos agricultores.

\section{Características, evolução e funções das redes de diálogo profissional na agricultura biológica}

Nossa abordagem das redes de relações é proveniente dos trabalhos em socioantropologia do conhecimento e de estudos do Gerdal sobre os fundamentos da mudança técnica na agricultura (DARRÉ et al., 1989; DARRÉ, 1996). Ela baseia-se na idéia segundo a qual as práticas dos agricultores, as escolhas que eles fazem e as consequientes mudanças em suas atividades não são o produto de uma aplicação do conhecimento científico ou de mensagens técnicas dos agentes da assessoria, mas de uma atividade de reflexão dos agricultores, a partir da qual eles analisam as situações, definem o que é necessário fazer e como fazer e tentam encontrar as soluções para um problema.

Mais precisamente, tratamos de uma atividade de produção de conhecimentos para a ação (GERTZ, 1983; BERGER; LUCKMANN, 1966) que se funda sobre o sentido que damos às coisas (WEBER, 1956) e pelo qual se elaboram e se transformam as normas de trabalho, ou seja, as concepções ${ }^{2}$ que guiam a prática. Neste sentido, ela é uma composição central da qualificação profissional, ${ }^{3} \mathrm{com}-$ ponente que está em jogo particularmente no caso da "conversão" ou da instalação da agricultura biológica, quer dizer, é uma qualificação que se dá por meio de situações que remetem, junto às mudanças que elas supõem, a um trabalho específico de resoluções de problemas e de "ajuste" de novas normas técnico-econômicas.

Enquanto tal, essa atividade de reflexão se opera por uma parte importante ou através do diálogo entre agricultores. É uma atividade coletiva que recoloca as possibilidades de troca que oferecem as redes de relações que os agricultores constituem entre eles, junto a suas relações "habituais" de trabalho; as redes profissionais, tais como as entendemos aqui, são compreendidas em sua dimensão informal e local (pode-ríamos falar de redes de visinhança) e elas se distinguem das redes institucionais às quais os agricultores podem, por outro lado, pertencer.

2 A noção de concepção se refere não a uma visão ideológica das coisas, mas ao pensamento técnico. É, por exemplo, a maneira de avaliar a doença e de encarar o tratamento dos animais, a maneira de perceber a qualidade de um solo, a relação entre o solo e as plantas etc. Essas concepções guiam mais diretamente a ação prática. 3 Entendemos por isso não só um nível de formação ou mesmo um nível de experiência, mas um conjunto de capacidades próprias à agricultura biológica: por exemplo, controlar técnicas complexas, adaptar-se às novas condições de introdução dos produtos no mercado, tratando de segurar as oportunidades, mas também de negociar com transformadores e distribuidores as condições de venda, os preços e as normas de qualidade. 


\section{Duplo pertencimento profissional dos agricultores e elaboração de referência na agricultura biológica}

Os primeiros estudos sobre as redes de relações na agricultura biológica desenvolvidos a partir de 1991 na Bretanha e na região do Loire (RUAULT, 1992; LÊ GUEN; RUAULT, 1994), partiam da hipótese segundo a qual, se os agricultores, por minoritários que fossem, já tinham tornado seus modos de produzir viáveis, fora de todo padrão científico e técnico, eles se apoiariam nas dinâmicas das trocas da natureza, de forma a favorecer essa atividade de produção de conhecimentos. Como são estruturadas essas relações, tanto localmente como em escalas mais largas, e qual é seu papel?

Primeira constatação: os agricultores bios estão afastados uns dos outros, por certo, mas nem por isso estão isolados onde vivem e trabalham. A maior parte deles tem relações com seus vizinhos "convencionais" baseadas na "ajuda mútua", a co-propriedade de material, e conversas entre si. $\mathrm{O}$ fato de fazer agricultura biológica é raramente mencionado como uma causa de isolamento. ${ }^{4}$ Dito de outro modo, pode haver diferenças de concepções e da maneira de produzir, até mesmo desacordos, mas nem por isso essa situação conduz à ausência de diálogos. Esses diálogos tratam de questões diversas, tais como o manejo do solo, a alimentação do rebanho e os custos de produção. Em compensação, constatamos que, naquele momento, a agricultura biológica ou as suas técnicas não eram abordadas enquanto tais.

Paralelamente, os agricultores bios constituíram entre eles redes "específicas". No âmbito das sub-regiões, existe, em todos os casos estudados (sub-regiões Bretons e Mayenne), uma estrutura associativa: GAB, GVA biológico ou Civam biológico. Os agricultores se encontravam nessas associações para reuniões ou para se visitarem, mas esses encontros eram ocasionais. Não obstante, em uma escala mais reduzida, a de uma microrregião (correspondente a um raio de $30 \mathrm{~km}$ no máximo), as relações eram suficientemente densas a ponto de serem consideradas verdadeiramente como redes de diálogo. A proximidade geográfica, uma mesma produção e, desse fato, a possibilidade de poder partilhar pro- blemas comuns são os principais critérios de constituição dessas relações. A idade do agricultor, o tamanho do estabelecimento e sua distinção ou ainda o sistema técnico (mais ou menos intensivo, por exemplo) não exercem um papel importante. Essas relações podem basearse sobre formas concretas de cooperação, tais como a troca de material especializado ou a organização para a venda de produtos.

Com a inserção em redes de vizinhança de um lado, em redes específicas de bios de outro, os agricultores bios caracterizam-se por um duplo pertencimento profissional. Essas duas formas de relação parecem exercer papéis complementares em diversos níveis da construção da identidade profissional - reconhecimento como agricultor e como "profissional" no âmbito da rede local, legitimação de um modo específico e diferente de produzir na rede de bios (com um peso variável de uma ou de outra das duas redes segundo os agricultores), mas sobretudo na elaboração de "normas" (ou referências) e a resolução de problemas concretos. Como havíamos notado antes, as questões técnicas ou econômicas relacionadas especificamente aos bios - homeopatia, utilização de um material especializado (capina térmica, por exemplo) - são mais discutidas entre os agricultores. Mas, em seguida, no momento em que se trata de colocar em prática os métodos (escolher uma data de semeadura, por exemplo), as normas técnicas biológicas são confrontadas ou avaliadas frente ao sistema de referências local. Os agricultores procedem, então, por ajustamento entre diversos sistemas de normas. Este trabalho de ajustamento é próprio a todo processo de adequação das práticas em uma situação de mudança. Parece, no fundo, um processo de resolução de problemas para os quais não existem soluções prontas, o que é particularmente o caso em agricultura biológica, uma forma de agricultura para a qual não existe um itinerário técnico típico e que busca "empurrar" ao máximo uma lógica de ajustamento ótimo, caso a caso, entre os diferentes fatores de produção.

No que concerne às trocas específicas entre os agricultores bios, pudemos colocar em evidência o papel exercido por elas para resolver problemas ligados à comercialização dos produtos: risco de evolução das condições de coleta do leite, problemas de perspectiva

4 Constatamos que, quando os agricultores estavam isolados, tratavam-se de pessoas de origem geográfica ou social exterior (neo-rurais) ou que estavam fazendo uma produção diferente (por exemplo, horticultura exposta diretamente ao vento e cabras) ou ainda chegando ao fim do ciclo de exploração e sem sucesso. Encontramos os mesmos critérios de isolamento para o restante de agricultores ditos "convencionais". 
para a venda da carne etc. Entretanto, é mais por um diálogo informal e direto entre os agricultores, em reuniões da associação sub-regional, que os problemas têm sido postos, podendo em seguida exercer um papel para apoiar a realização de projetos.

Nós lembramos que, nesses dois níveis de relação, os diferentes tipos de "cooperação" existentes no plano material ou no plano das idéias testemunham uma certa capacidade de gestão da diversidade. De um lado, diversidade própria ao meio agrícola local e, de outro, diversidade interna ao meio dos bios. Neste último caso, essa diversidade se traduz em procedimentos de acesso aos bios (entendidos como as razões que levam a escolher os biológicos e as trajetórias de conversão), a sistemas de exploração e modos de conduzir concretamente a produção extremamente variáveis (ver tabela em anexo).

\section{Evolução das configurações sociais e das normas de trabalho em bios}

Os agricultores que hoje passam a trabalhar com agricultura biológica contribuem ainda mais para ampliar essa diversidade. Eles não possuem um único perfil, mas podemos pôr em evidência uma tendência comum em seu percurso. Eles abordam a agricultura biológica de um modo menos ideológico ${ }^{5}$ que o de seus predecessores, a partir de um raciocínio econômico ou técnico-econômico mais afirmado, que integra dois fatores importantes: o mercado e os custos de produção.

Entretanto, isso não quer dizer que eles sejam oportunistas. A escolha pela agricultura biológica é frequientemente o resultado de uma evolução já iniciada desde algum tempo nos estabelecimentos, buscando a diminuição de custos e a uma gestão econômica mais apurada. As oportunidades de venda oferecidas pelo mercado são, nesse caso, mais um elemento desencadeador do que uma causa da passagem à agricultura biológica. Acreditamos, por isso, que a passagem à agricultura biológica é mais diretamente ligada a um fator "externo" ao estabelecimento: por exemplo, no momento em que algumas indústrias de produção e transformação de aves "certificadas" incitam seus produtores a passar de um sistema de agricultura convencional a um sistema de agricultura biológica. As modificações das condições e normas de produção não são necessariamente muito importantes. ${ }^{6}$

A oposição agricultura biológica "ética" e agricultura biológica "oportunista" algumas vezes coloca-se na frente do debate sobre a evolução dessa forma de produção, por isso aparece de uma forma por demais simplista para dar conta da diversidade atual dos agricultores bios. A chegada de novos produtores traduz-se, entretanto, pelo alargamento das concepções e dos modos de produzir em agricultura biológica, na medida em que elas convivem com as concepções das gerações precedentes, já heterogêneas. A agricultura biológica cobre hoje um leque de quase todos os tipos de estabelecimentos e agricultores (BONNAUD; SOULARD; LEISEGNEUR, 1999). Como então se dá a recepção desses "recém-chegados"? Como evoluem as dinâmicas das relações internas aos bios, bem como as relações com os agricultores convencionais?

\section{Novas pontes entre agricultores bios e convencionais, novas "clivagens" internas aos agricultores bios e novas normas de produção}

No início dos anos 90 , poucos agricultores faziam parte dos grupos de desenvolvimento, tais como os GVA ou os Ceta. ${ }^{7}$ Dentre aqueles que tornaram-se agricultores bios hoje e que desenvolvem ou já tinham relações com os bios, um certo número está integrado a essas redes de desenvolvimento, ocupando, às vezes, algumas responsabilidades. Assistimos assim, em conseqüência dessas novas formas de multipertencimento, a certos "cruzamentos" entre as redes institucionais de agricultura biológica e "convencional".

Paralelamente, no que concerne especificamente às redes de agricultores bios, podemos observar a apari-

\footnotetext{
5 Embora mesmo para as geraçōes precedentes nenhuma ideologia nunca tenha dito o que seria necessário fazer concretamente para produzir e como fazê-lo. A conversão para agricultura biológica corresponderia também a um raciocínio prático, mas com critérios diferentes dos de hoje.

6 Podemos dizer, aliás, que, para as aves, as cartilhas foram elaboradas por essas empresas integradoras.

7 GVA: Groupement de Vulgarisation Agricole. Ceta: Centre d'Etude Technique Agricole.

8 Existem também GVA de agricultura biológica, mas que se aparentam mais, talvez, a um GAB que a um GVA, pelo menos era o caso, no começo, dos primeiros GVA de agricultura biológica.
} 
ção de algumas clivagens, cujas principais são: o nível econômico (tamanho do estabelecimento e nível de renda), o grau de integração ao mercado e a maior ou menor proximidade com o mundo do desenvolvimento "convencional". Com a conversão de grandes estruturas (de leite, notadamente na Bretanha), aparece uma distinção do tipo "grande-pequeno" ou "intensivo-extensivo".

Dentre os novos agricultores, alguns dão maior importância ao desempenho técnico na qualificação profissional. Próximos dos técnicos, esses agricultores fazem parte de redes de referência que ganham espaço entre os bios e são frequientemente solicitados a fazer visitas. No momento em que eles que ocupam os postos de responsabilidade das associações de agricultores bios (o que nem sempre é o caso), uma parte dos agricultores bios mais "antigos" se sentem desapossados dos valores que quiseram afirmar: viver em pequenas estruturas, reduzir a dependência a montante e a jusante, permanecer autônomo vis-à-vis ao "aparelho oficial" de desenvolvimento etc. Temos então uma clivagem entre o que poderíamos chamar de abordagens mais técnicas e as outras, tanto ligadas ao lugar que é destinado aos agricultores no setor institucional do desenvolvimento, onde eles constituem, às vezes, uma espécie de "modelo" da agricultura biológica, quanto às diferenças de concepções entre elas mesmas.

Localmente, no interior das redes de diálogo, a agricultura biológica torna-se hoje uma variante dentre outras no sistema de normas, mesmo se é uma variante ainda vaga e instável. As técnicas biológicas (a capina mecânica, por exemplo) ou problemas próprios aos bios (condições de comercialização, qualidade dos produtos) são doravante discutidos enquanto tais. Na mesma linha de raciocínio, assinalamos que a eventualidade de uma passagem dos agricultores convencionais à agricultura biológica pode ser o objeto de debates entre os agricultores no quadro de suas relações habituais de trabalho (RAGOT, 1998).

No que concerne à evolução dos sistemas de normas, teríamos, então, um duplo processo:

- localmente, a fronteira entre a agricultura biológica e outras formas de agricultura parece se atenuar;
- no interior dos grupos mais institucionais de desenvolvimento, se a agricultura biológica é abordada sob um ângulo bastante geral, ela está presente, entretanto, como um componente possível dos modelos de agricultura "sustentável" ou "racional", tornando-se uma norma legítima da modernização. $\mathrm{O}$ alargamento das concepções e dos modos de produção em agricultura biológica contribuiria assim para colocar em debate o que pode querer dizer hoje em agricultura ser moderno ou não.

Finalmente, opera-se, ao mesmo tempo, uma complexificação dos sistemas de normas e de configurações das relações profissionais; os lugares e as escalas de diálogo entre os agricultores não se substituem uns pelos outros, mas, antes, se sobrepõem. Aliás, esse processo não é próprio à agricultura biológica. Ele traduz o que se passa no conjunto da agricultura com a multiplicação das posições de multipertencimento dos agricultores. Os agricultores, se permanecem primeiramente integrados a redes locais, estão hoje presentes - e em número crescente - em lugares de discussão, constituídos em torno de critérios e funções muito diversas (funções econômicas ou comerciais, redes especializadas em torno de uma produção etc.), diretamente ligadas ao exercício de sua atividade profissional.

Vejamos agora como isso se insere no desenvolvimento e como a agricultura biológica toma lugar no conjunto dos atores e organismos que compõe esse setor. Uma das questões que podem ser postas, ao olhar do que foi dito, é a de saber se a integração dessa nova forma de produção é acompanhada de uma evolução das formas e das concepções da assessoria de agricultura.

\section{Organização, concepções e práticusts de assessoria em agricultura biológica}

Nós abordamos o desenvolvimento agrícola por meio da noção de campo profissional: um conjunto de atores (agricultores, agentes e organismos) ${ }^{9}$ estruturados pelas relações que eles têm entre eles e pelas posi-

9 Os organismos que compðem o setor de desenvolvimento e de assessoria na agricultura são classificados como: 1. Organizaçð̄es Profissionais Agrícolas (OPA - Organization Profissionelles Agricoles), geridas pela profissão: sindicatos ou agrupamentos de produtores de um lado, Câmaras de Agricultura e Adasea, de outro; 2. organismos econômicos: cooperativas ou empresas privadas a montante e a jusante; 3 . organismos de serviço: Controle Leiteiro, centros de gestão, 
ções de uns em relação aos outros ao redor dos enfrentamentos, dos interesses e dos objetivos específicos (BOURDIEU, 1984). Em relação aos agentes e aos organismos, essas posições se traduzem em missões e papéis mais ou menos "reconhecidos". São também posições de um dado momento do debate.

\section{Características e evolução do setor do desenvolvimento em bios}

No que concerne ao desenvolvimento dos bios, ele é levado por um conjunto de atores que tem como objeto de trabalho a agricultura biológica, atribuindo-lhe meios específicos, mas ao que parece é difícil fazer disso um setor à parte. Com efeito, o modo pelo qual se organiza, as ações que são desenvolvidas e os debates que a permeiam estão ligados ao que se passa no conjunto do setor agrícola, isso porque as primeiras organizações de bios se constituíram como um contrapoder ao "aparelho de desenvolvimento" oficial. A partir do caso da Bretanha (RUAULT, 1997), ${ }^{10}$ daremos alguns elementos de descrição desse conjunto, permitindo, antes de tomar conhecimento da questão dos conceitos e práticas da assessoria em vigor, compreender as evoluções e desafios em curso." Esses elementos não determinam, enquanto tal, as práticas dos agentes; entretanto, eles constituem o quadro (institucional, mas também um quadro de debates) dentro do qual elas se inscrevem.

\section{Diversidade da oferta da assessoria em bios e estruturação acelerada}

Se levarmos em consideração o número de assessores especializados (identificados como tais), a asses- soria dos agricultores bios ainda era quase inexistente há alguns anos, mesmo quando alguns fornecedores de "entradas", tais como Lemaire Boucher, ou agricultores independentes (também fiscais) prestavam um serviço de assessor. É da parte dos produtores a constituição das primeiras organizações. Na Bretanha, os Agrupamentos de Agricultores Bios (GAB - Groupements d'Agriculteur Biologiques), criados entre 1980 e 1987, à razão de um ou dois por sub-região, em princípio não tinham salários e atuavam mais com uma função política de "defesa e promoção da agricultura biológica" que de assessoria. Os primeiros postos, geralmente precários, datam de 1990. Nas câmaras de agricultura, os primeiros "assessores bios" datam do começo dos anos 90. Tratam-se, na maior parte deles, de agentes já com postos "colocados à disposição" para a agricultura biológica, geralmente em meio período.

Apenas nos últimos três anos que vimos aumentar muito rapidamente o número de postos de agentes. Em 1996, contamos, na Bretanha, o equivalente a sete agentes em período integral nos $\mathrm{GAB}$, e três agentes em igual período de tempo nas câmaras. Três anos depois, o número de "agentes de desenvolvimento" 12 intervindo diretamente junto aos agricultores bios $^{13}$ foi multiplicado quase por três, passando de 10 a 27 agentes em período integral, com um crescimento mais forte nos GAB (18 ETP) que nas câmaras ( 9 ETP). Estes últimos consideram que uma parte da assessoria deve ser preenchida por assessores não especializados.

De fato, se abordamos a assessoria do ponto de vista dos agricultores, perguntando a eles quais são seus negócios concretamente, não podemos ter somente agentes em agricultura "biológica". Os agricultores também solicitam técnicos não especializados em agricultura biológica, mas especializados em uma produção (legumes, porcos e aves), técnicos para a produção de leite, técnicos em gestão e veterinários. Os agentes "técnico-

\footnotetext{
cooperativas de inseminação artificial e de controle do crescimento no setor de criações - os serviços aos agricultores geralmente são pagos; 4 . no que tange à agricultura biológica, é necessário acrescentar os organismos de controle e de certificação.

10 Estudos realizados pelo Grupo de Estudos Pluridisciplinar em Agrobiologia da Bretanha (GEPAB - Goupe d'Etude Pluridisciplinaire Agrobiologie Bretagne).

11 Do ponto de vista metodológico, realizamos entrevistas aprofundadas, junto aos agentes de desenvolvimento (GAB e câmaras pesquisadas até em 90\%), com uma parte dos agentes de empresas econômicas e também com uma amostragem de agricultores sobre suas relações com os agentes da assessoria e a visão que eles têm disso. Por outro lado, analisamos a documentação profissional de vários anos, de 1996 até hoje.

12 Agrupamos sob o termo "agentes de desenvolvimento" os animadores e técnicos dos GAB e das câmaras pela diferença com os agentes das empresas e dos organismos de serviço.

13 Um certo número de agentes não está em relação đireta com os agricultores e/ou não para uma intervenção da assessoria.
} 
comerciais" das empresas, cada vez mais numerosos e, alguns deles, especializados em agricultura biológica há mais de cinco anos, exercem igualmente um importante papel. Uma primeira característica da oferta de assessoria em agricultura biológica é, então, a grande diversidade de agentes e organismos que intervêm junto aos agricultores. Isso levando em conta que, da parte destes últimos, o grau de relação com os técnicos é muito variável.

Uma segunda característica desse setor é um processo de estruturação relativamente rápido dos atores que o compõem, pela sua presença em redes sociais e pela criação de organismos regionais. Na Bretanha, são, por exemplo, a Federação Regional dos Agricultores da Bretanha (Frab - La Fédération des Agriculteurs de Bretagne), criada em 1987, ou a L'Interprofession Bio Bretonne (IBB), criada em 1995 e que reúne produtores, consumidores, transformadores e distribuidores. Esse processo, hoje muito disseminado, ${ }^{14}$ traduz a existência prévia de um certo nível de organização dos agricultores e parece responder a uma vontade dos agricultores da agricultura biológica, de se constituírem como interlocutores de peso vis-à-vis aos poderes públicos, mas também às organizações profissionais clássicas, às quais são, às vezes, preparadas estratégias de "recuperação".

Para precisar melhor, é necessário reposicionar esse processo frente à evolução do lugar da agricultura biológica nessas organizações e nas câmaras em particular.

\section{O lugar da agricultura biológica no desenvolvimento institucional e a distribuição das funções da assessoria entre organizações: desafios e evolução}

Os primeiros assessores em agricultura biológica das Câmaras de Agricultura encontravam-se numa posição relativamente frágil; se ocupar da agricultura biológica representava um risco de marginalização no interior da estrutura. Pouco interesse é dado ao que eles fazem e não há diretrizes ou objetivos precisos concernentes a seus trabalhos. Se eles têm uma legitimidade fraca, eles dispõem, em compensação, de uma certa margem de manobra, que é um trunfo para organizar seu trabalho no quotidiano. Esta legitimidade é buscada junto aos agrupamentos de agricultores biológicos sobre os quais se apóiam para ter acesso ao "campo", para definir os conteúdos das ações e realizá-las. Inicialmente, alguns assessores estavam, aliás, colocados à disposição dos GAB. Sob uma aparente distribuição de tarefas - apoio técnico para as câmaras, defesa dos agricultores e promoção da agricultura biológica para os $\mathrm{GAB}$-, constatamos, assim, em diversas sub-regiões, uma colaboração informal e direta entre os agentes, manifestando-se por um funcionamento "em binômio".

Hoje, com o reconhecimento da agricultura biológica, os assessores adquirem uma legitimidade nova e seu trabalho se inscreve doravante num conjunto de objetivos e de programas "institucionais". No campo, a relação entre agentes dos GAB e das câmaras é marcada por uma concorrência nova. Essa concorrência remete primeiro a um aumento do número de assessores, que modifica a relação entre oferta e demanda. No que concerne à "demanda", a passagem obrigatória dos agricultores pelos assessores para constituir seu processo de conversão é, ao mesmo tempo, um desafio financeiro e um desafio "de acesso ao campo". Mas um segundo fator intervém, o fato de que os GAB têm reforçado a função de apoio técnico através de atividades tais como a formação, a publicação de documentação técnica e a animação de grupos. Essa evolução parece responder a uma vontade de permanecer mais presente no campo e de não deixar as câmaras "se ocuparem da agricultura biológica". Acrescentamos ainda que, no que se r ffere a essa assessoria técnica, tanto os agentes dos $\mathrm{GAl}$, como os das câmaras encontram-se também em concc rência com os técnicos das empresas, consideradas pelos agricultores como exigentes tecnicamente e com um desempenho muito bom.

Passamos assim de uma situação de colaboração não formalizada entre agentes, mas real, a uma situação em que as relações são formalizadas pelas convenções que supõem a otimização da distribuição dos papéis (e dos meios financeiros), mas em que, na verdade, há uma menor cooperação e uma concorrência que vai, às vezes, chegar até uma tensão real. Para os agricultores, isso resulta em uma certa desarmonia na oferta de assessoria.

14 Um exemplo é dado em Rhône Alpes, com a criação do Corabio para reagrupar as associações de quatro départements. 
Para os agentes, isso leva a reduzir sua margem de manobra. Os desafios estratégicos tomam em seus trabalhos um lugar cada vez mais importante em detrimento daqueles do desenvolvimento propriamente dito. Atualmente, as ações parecem às vezes mais definidas ponto a ponto, conforme as oportunidades de financiamento $e$ de ocupação do terreno, somente a partir de uma reflexão sobre as expectativas dos agricultores, sobre os objetivos e os conteúdos de ação a definir para responder a isso. Vejamos agora mais precisamente o que recobre essas ações e o modo como elas são concebidas.

\section{Atividades e concepções das assessorias: fundo comum e variantes}

Até agora, o conjunto dos assessores em agricultura biológica das câmaras e dos $\mathrm{GAB}$ se posiciou em oposição ao modelo de desenvolvimento "dominante", correspondendo, segundo eles, ao modelo da difusão de receitas, a uma abordagem por demais "reduzida" do estabelecimento e a uma relação vertical com os agricultores. Contrariando esse modelo, eles seguem uma visão do desenvolvimento cujos elementos comuns de referência são:

- uma abordagem global do estabelecimento, associada à idéia de "um trabalho de fundo" oposta a uma abordagem no âmbito da tecnologia de ponta;

- a vontade de favorecer as trocas entre agricultores e de instaurar uma relação de troca entre o assessor e o agricultor, vontade que caminha junto com a preocupação de levar em conta os conhecimentos elaborados pelos agricultores. Como diz um assessor: "em agricultura biológica, acontecem muitas coisas no dia-a-dia, os agricultores inovam enormemente, mais que as câmaras de agricultura".

Todavia, além desse pano de fundo comum, os modos concretos de intervir e os modelos conceituais aos quais eles se referem são mais heterogêneos e não diferem necessariamente do que se pratica comumente no desenvolvimento agrícola. Esse fundo comum parece as- sim acentuar mais as posições ideológicas gerais, dando lugar a uma visão um pouco estereotipada e não a uma análise crítica precisa dos métodos e conceitos utilizados na assessoria de agricultura. Se tomamos o exemplo da "abordagem global" (ou "abordagem sistema"), ela constitui uma ferramenta correntemente utilizada, e isso numa perspectiva "de ajuda à decisão" que se diferencia da difusão de receitas.

Observamos, portanto, variantes de um assessor a outro, sabendo que o trabalho dos assessores se caracteriza primeiro por um campo de atividades e de funções extensas e relativamente dispersas, à imagem ainda do que se passa no setor da assessoria em geral (LEMERY, 1991). A maneira como os agentes apresentam essas atividades ressalta as categorias seguintes: o apoio ou $a$ assistência técnica, associada geralmente a formas de intervenção individuais (visitas de acompanhamento, elaboração de processos de conversão), e a formação ou a animação, que correspondem mais a formas de intervenção coletiva (seguidas de grupos de agricultores, jornadas temáticas etc.). Paralelamente, mencionam as atividades de experimentação (nas câmaras), de comunicação e de promoção da agricultura biológica (sobretudo dentro dos $\mathrm{GAB}$ ) ou ainda a organização do parrainage. ${ }^{15}$

Quanto aos modos diferentes de abordar estas atividades, destacaremos os dois pontos seguintes:

- entre os agentes pesquisados, alguns concebem a assessoria dentro de uma lógica de aporte de conhecimentos que permanece marcada por um modelo difusionista. Se há o trabalho em grupo, ele é centrado no objetivo da formação ou da aprendizagem. A demanda dos agricultores é então mais apreendida em termos de temas, sem que haja da sua parte um trabalho específico de formulação de objetivos;

- para outros, a prioridade é dada às trocas entre agricultores para "partilhar as experiências". Uma das condições para que o grupo "ande bem" é a de aproveitar o tempo para "definir bem os objetivos". Neste caso, a animação é considerada como "um meio para aprender a técnica" e como pertencendo a uma competência específica; como diz precisamente um assessor "é um ofício". Para os primeiros, ao contrário, há uma certa oposição

15 Relação direta e formal (fazendo o objeto de uma convenção) entre um agricultor experimentado - o padrinho e um agricultor que se inicia em agricultura biológica - e o afilhado, para ajudá-lo em seu procedimento de conversão ou de instalação. 
entre assessoria técnica e animação, esta última sendo considerada como alguma coisa anexa e por demais vaga.

\section{Evolução das formas de intervenção em agricultura biológica, interrogações $e$ paradoxos}

As tendências atuais de evolução das formas de assessoria em agricultura biológica traduzem bem essa diversidade de concepções e resultam em alguns paradoxos:

- o aumento das ações de formação nos $\mathrm{GAB}$ e nas câmaras (sob a forma de jornadas temáticas abertas a um público amplo ou sessões de vários dias do tipo Fafea) manifesta a importância sempre acordada da aquisição de conhecimentos como dado essencial da conversão ou da instalação;

- ao mesmo tempo, observamos (mais da parte dos GAB) um desenvolvimento das formas de trabalho baseado na troca entre agricultores, com a multiplicação dos grupos de troca, a parrainage ou ainda a ocupação do espaço pelas bolsas de trocas (para reagrupar e trocar matérias-primas entre os agricultores biológicos). No que concerne aos grupos de trocas, eles são constituídos principalmente na base de dois critérios: uma mesma produção e uma escala geográfica não muito extensa, de modo a se apoiar num nível mínimo de relações existentes, o que é considerado como um trunfo. Em Ille e Vilaine temos, por exemplo, um grupo que produz leite engarrafado e leite em caixa. Esses grupos são considerados como um meio de ajudar àqueles que chegam à agricultura biológica com problemas, mas em alguns casos o conteúdo e as modalidades de trabalho permanecem concebidos dentro de uma lógica de formação (uma jornada = um tema e um expositor). Vão no mesmo sentido;

- um outro elemento de evolução é a multiplicação dos programas de experimentação (mais nas câmaras, mas não unicamente), com o objetivo de produzir referências técnico-econômicas. Se observamos o modo como essas experimentações tomam lugar, constatamos que a definição dos temas, dos conteúdos e dos protocolos inscreve-se nos procedimentos relativamente institucionais e pré-estabelecidos, sem que seja verdadeiramente posta e discutida com os primeiros assessores a questão da utili- zação das referências - estas sendo antes uma ferramenta de assessoria.

Num contexto em que não se trata mais de "provar o interesse econômico e técnico da agricultura biológica", mas de dispor de ferramentas de assessoria pertinentes frente às expectativas dos agricultores por meio de tais programas e mais amplamente com as orientações que acabamos de evocar rapidamente, levantam-se várias interrogações, notadamente sobre a adequação entre a "oferta" de assessoria e as expectativas dos agricultores.

\section{Oferta de assessoria e expectativas dos agricultores, qual gestão da diversidade?}

Algumas dessas interrogações são colocadas em evidência mediante ao que os agentes de desenvolvimento exprimem quando explicam as dificuldades que encontram e as interrogações sobre o futuro de seu trabalho. Ressaltam-se duas coisas em particular:

- uma dificuldade relativa à demanda, às vezes ligada com o fato de ter negócios com uma população de agricultores bios percebidos como heterogêneos tanto do ponto de vista dos sistemas técnicos como das expectativas vis-à-vis da assessoria;

- uma preocupação quanto à participação nas ações propostas, julgadas muitas vezes insuficientes ou não conforme os desejos dos agentes, ou ainda uma dificuldade para "mobilizar durante longo tempo". Os aspectos trazidos pelos assessores sobre os agricultores que participam mais ressaltam que se trata mais "dos que têm vontade de praticar a técnica", de agricultores "suficientemente competentes que chegam a se tornar disponíveis" ou ainda "preferencialmente os jovens".

Não encontramos uma constante de desenvolvimento agrícola, levando em conta a diversidade dos agricultores e mais precisamente a dificuldade proporcionada por tal diversidade como um componente de apoio para definir as ações e finalmente como um trunfo a explorar quanto à dinâmica da inovação e da evolução das normas de produção. 
Se colocarmos em paralelo, no que se refere à agricultura biológica:

- de um lado, o fato de que os agricultores bios que participam mais nas ações de desenvolvimento são aqueles que, pelo seu método de trabalho, são os mais próximos de uma visão "técnica";

- de outro lado, o fato de que, entre os agricultores não biológicos, os mais interessados para passar à agricultura biológica são também aqueles que estão inseridos nos grupos de desenvolvimento instituídos - suas abordagens baseadas sobre uma lógica técnico-econômica de ponta e uma integração das preocupações ambientais, correspondentes ao modelo de agricultura racional pregada doravante pelas instituições de desenvolvimento (RAGOT, 1998) - e que são muitos os agricultores que estão dispondo de um capital sociotécnico elevado: estabelecimentos de tamanho relevante e de bom desempenho, um nível elevado de formação,

podemos nos questionar se a agricultura biológica não está se tornando um modelo reservado a uma elite técnica, definindo-se não apenas pelos critérios acima, mas pelo fato de se tratar de agricultores que respondem mais diretamente às exigências qualitativas e quantitativas da indústria de transformação e da grande distribuição.

Não procuramos aqui defender mais um modelo de produção biológica que outro, mas chamar a atenção sobre os efeitos da interação entre as dinâmicas de evolução em curso na perspectiva dos agricultores, em que assinalamos que essas dinâmicas eram marcadas por um alargamento das concepções e do modo de produzir em agricultura biológica, mas também pelo surgimento de clivagens, e sobre o modo como o desenvolvimento se interessa por esta forma de produção e leva em conta essas dinâmicas. A legitimação que a agricultura biológica toma como objeto no interior das instituições pode conduzir a efeitos de seleção se os modos de intervenção tendem a aumentar as clivagens, por exemplo, só respondendo às expectativas de alguns agricultores, entre outros, já que aquelas que estão mais claramente expressas são frequientemente oriundas de agricultores mais próximos aos técnicos. Se a diversidade é explorada, isso pode, ao contrário, contribuir com uma ampliação da base social dos agricultores à procura de alternativas e que se beneficiem de uma legitimidade e de um reconhecimento no meio agrícola.

Para precisar as coisas, diremos que certas formas de intervenção e de trabalho (da parte dos agentes) tornam-se mais difíceis que outras de ter em conta a diversidade de agricultores, levando a reduzir ou a ampliar o público alvo do desenvolvimento. Quando as ações de desenvolvimento e a relação técnico-agricultor são concebidas unicamente em termos de aprendizagem ou quando os métodos de trabalho no interior de um grupo se apóiam antes de tudo sobre os instrumentos técnicos, isso limita a participação dos agricultores àqueles que têm vontade "de se formar por se formar", àqueles que são "próximos dos técnicos" em razão de sua formação ou de uma certa herança cultural.

Se, por outro lado, os conteúdos das ações são definidos com os responsáveis profissionais (enquanto representantes "da base"), em termos de temas mais do que de questões a tratar, disso resulta freqüentemente uma certa defasagem com as expectativas do restante dos agricultores. Uma dificuldade reside no fato dessas questões serem raramente formuladas enquanto tais, ou seja, como problemas diretamente tratáveis. As enquetes junto aos agricultores mostram que o que eles expressam são antes dificuldades do que aspirações. São também expressas as questões técnicas ou técnico-econômicas (no sentido amplo) "de ponta" e "específicas", isto é, diretamente ligadas a atividades e aos problemas do agricultor sobre sua exploração agrícola. Mas os assessores tendem então a considerar que os agricultores vêem as coisas de uma maneira "muito técnica" e "pouco global".

Não seria necessário então conduzir uma reflexão sobre os meios de acessar mais precisamente esse modo sobre os qual os agricultores, em sua diversidade, questionam-se. Volta-se também a se indagar sobre os meios de apoiar as dinâmicas de troca entre os agricultores, em particular nas redes informais, enquanto eles constituem um suporte de discussão e um lugar onde esses problemas podem ser formulados, mais frequientemente de maneira diferente da que os agentes têm acesso unicamente pelas redes institucionais.

Do lado das associações de produtores bios, o número de adeptos dos $\mathrm{GAB}$ permanece relativamente elevado (uma pequena parte dos agricultores bios em média sobre a Bretanha) e superior ao que é observado pelos grupos tais como GVA ou Ceta (dos quais estima- 
se que participam menos de um terço de agricultores). Constatamos uma certa dificuldade em permanecer junto ao grupo de agricultores bios e de ser um espaço onde continua a se expressar uma diversidade de concepções e de modos de produzir. Isto se traduz, por exemplo, na composição de certos grupos de trocas (em leite notadamente): os maiores estabelecimentos, os mais tecnicamente de ponta estão super-representados, em detrimento aos menores ou sistemas de venda direta, que funcionam com outros critérios de eficácia técnico-econômica diferentes dos primeiros. Da mesma forma, certos tipos de agricultores antes muito ativos nas $\mathrm{GAB}$ estão hoje aposentados. A este título, podemos perguntar se a ênfase colocada no conjunto das atividades propostas (para alguns dos grupos) sobre a assessoria técnica e a formação não caminha, ainda, no sentido de um privilegiamento da população que participa.

\section{Elementos de conclusão}

Atualmente, a maneira pela qual a agricultura biológica está integrada ao conjunto do desenvolvimento agrícola demonstra que, se ela reflete bem o início de novas formas de conceber o trabalho do agricultor, sua integração enquanto sistema, doravante considerado como pertinente diante de certas normas de modernização da agricultura - aquelas associadas aos conceitos "de agricultura sustentável" ou agricultura "racional" -, não abre espaço, forçosamente, a novas formas de assessoria. Tudo se passa como se a instalação de um setor de conselho em agricultura biológica se fizesse por integração do objeto técnico "agricultura biológi$c a$ " nas formas habituais de intervenção de assessores, sem que haja, necessariamente, uma reflexão sobre os objetivos e os meios de colocá-la em prática, por meio de acompanhamento que leve em conta uma dinâmica própria dessa forma de agricultura e das dimensões, tais como a vontade de autonomia técnica e econômica dos agricultores, que, se não são elas específicas à agricultura biológica, nela são particularmente firmadas.

Teríamos, então, ao mesmo tempo que um reconhecimento da agricultura biológica, um fenômeno contraditório quanto à maneira como ela é considerada, apresentando duas tendências: de um lado, uma abertura de normas e de conceituação da produção agrícola e do trabalho do agricultor e, de outro, uma integração com $n$ modelo técnico no interior de um sistema de normas estabelecidas. Isto no que se refere às normas de produção (ausência de critérios, por exemplo, ao levar em conta somente "rentabilidade técnica ou econômica") e à maneira de prever a relação entre pesquisa, desenvolvimento e agricultores.

Nesse aspecto, ressaltamos que é sem dúvida um paradoxo que encontramos em todo processo social de integração de um grupo ou de um projeto "minoritário". Entretanto, podemos nos perguntar, nesse caso, onde a agricultura biológica seria integrada ao sistema de normas estabelecidas, se ela pode permanecer como uma alternativa aos modelos de produção que mostraram seus limites, se ela pode manter em seu bojo um projeto social e não somente um projeto técnico. Quando falamos de projeto social, queremos dizer, por exemplo, que se favoreça a conservação da agricultura nas regiões "marginalizadas" pelo modelo produtivista ou que se permita uma revalorização de certas produções (carne em sistemas extensivos) ou ainda de certos sistemas tais como os "pequenos sistemas" em venda direta com alto valor agregado. Atualmente, a taxa de instalação de neo-rurais é mais elevada em agricultura biológica que no resto da agricultura, em um contexto no qual quem procura manter o emprego agrícola é um vencedor.

No que concerne à relação entre pesquisa, desenvolvimento e produção, as dimensões mencionadas acima - uma vontade de autonomia técnica e econômica ampliada da parte dos agricultores -, parecem traduzir de maneira exemplar na agricultura biológica as novas formas de relações, as quais os agricultores, de uma maneira geral, aspiram com os agentes técnicos e econômicos com os quais são levados a trabalhar: as relações baseadas mais sobre uma divisão da produção de conhecimentos e uma cooperação na definição de tudo que se refere à evolução dos (seus) modos de produção. Nesse sentido, e mais que um caso específico, a agricultura biológica se constitui em revelador de um questionamento geral sobre a evolução das relações entre especialistas e agricultores, assim como sobre o papel dos agentes de desenvolvimento num conjunto de relações mais e mais complexas e que não pode mais se reduzir a uma relação bilateral com o agricultor.

Não seria necessário, inicialmente, considerar o papel das associações de produtores como os lugares onde os agricultores, e não somente estes que estão em vias de 
conversão, reforçam seu ponto de vista político e técnico para poder negociar em seguida as ações, as orientações de desenvolvimento. Para os agentes de desenvolvimento, tratar-se-ía de considerar as trocas entre agricultores, se tomamos o caso do apoio aos grupos, por exemplo, numa lógica de formulação de problemas, de elaboração de proposições e de respostas a questões colocadas sobre o futuro da agricultura biológica (a partir do que eles vivem concretamente), mais que de formação ou de apropriação de conhecimentos. É, na verdade, uma reflexão sobre como colocar no centro das formas de trabalho (do ponto de vista dos objetivos perseguidos, dos métodos etc.) a atividade de produção de conhecimentos dos agricultores, com um objetivo explícito de reforçar as dinâmicas de reflexão e de organização coletivas. A capacidade dos agricultores de se constituir em interlocutores ativos a montante e a jusante, assim como de todos aqueles que intervêm hoje em agricultura biológica - e eles são cada vez mais numerosos -, parece-nos ser um desafio maior para o futuro dessa forma de produção. Isto se constitui em um jogo nas relações com esses interlocutores, a saber, por exemplo, a definição dos sistemas de normas, as normas de produção e de qualidade dos produtos, os preços e as formas de comercialização, tudo isso resume bem a evolução dos sistemas de produção na sua diversidade.

Essas questões remetem, da parte dos agricultores, a uma reflexão sobre a evolução de suas organizações, sobre o papel que eles desejam vê-las desempenhar. Da parte dos agentes de desenvolvimento, é uma reflexão específica sobre seu trabalho e seu papel. Considerá-las supõe a possibilidade de não ficar unicamente nas lógicas estratégicas.

\section{TABELA 1- OS AGRICULTORES BIOLÓGICOS: DIVERSIDADE DE IDENTIDADES PROFISSIONAIS E DE PROCEDIMENTOS* DE INSTALAÇÃO OU DE CONVERSÃO}

\begin{tabular}{|c|c|}
\hline Os procedimentos de acesso à agricultura biológica & O "modelo" do produtor \\
\hline $\begin{array}{l}\text { Nos anos } 60 \text { : } \\
\text { A recusa à modernização padrão } \\
\text { e ao modelo intensivo }\end{array}$ & $\begin{array}{l}\text { - agricultores de mais de } 55 \text { anos } \\
\text { - pequenas estruturas: } 25 \text { - } 35 \text { ha } \\
\text { - policultura/criação: leite - carne } \\
\text { quotas de leite: } 35 \text { a } 58.000 \text { l/ano } \\
\text { - conduta semi-extensiva }\end{array}$ \\
\hline $\begin{array}{l}\text { Um raciocínio técnico-econômico: } \\
\text { Em direção a um sistema "mais econômico e mais autônomo" } \\
\text { Adaptar um procedimento já engajado } \\
\quad \text { - extensificação } \\
\quad \text { - diminuição dos custos }\end{array}$ & $\begin{array}{l}\text { - agricultores instalados depois de } 1985 \\
\text { - buscar a melhor valorização dos produtos } \\
\text { - poucas entradas "tudo verde" } \\
\text { - combinação de produtos variados (cereal-leite, cereais-porcos, leite, } \\
\text { leite-came) }\end{array}$ \\
\hline $\begin{array}{l}\text { A busca de valor agregado: } \\
\text { A agricultura biológica, um espaço comercial para alguns produtos }\end{array}$ & $\begin{array}{l}\text { - estruturas de tamanhos diversos } \\
\text { - em alguns casos, somente uma parte do estabelecimento com } \\
\text { agricultura convencional } \\
\text { - cereais, aves, ovos }\end{array}$ \\
\hline
\end{tabular}

NOTA: * Os procedimentos são definidos a partir de dois tipos de dados:

- as razōes dadas pelos agricultores para explicar sua escolha de passar à agricultura biológica e sua escolha de fazer de tal ou tal modo;

- as etapas concretas de instalação do sistema de agricultura biológica ou da conversão ("como ela é feita", quais mudanças, como é operada). 


\section{REFERÊECIAS}

BONNAUD, T.; SOULARD, C.; LESEIGNEUR, A. Comment les agriculteurs abordent la conversion vers l'agriculture biologique? Propositions pour un dispositif d'accompagnement. Rapport Chambre Régionale d'Agriculture, Conseil Régional DRAF de Bourgogne. Bourgone: [s. n.], 1999. 96 p.

BERGER, P.; LUCKMANN, T. La construction sociale de la réalité. Paris: Méridien-Klincksieck, 1966/86.

BOURDIEU, P. Questions de sociologie. Paris: Les Editions de Minuit, 1984. $268 \mathrm{p}$.

DARRE, J. P.; LE GUEN, R.; LEMERY, B. Changement technique et structure professionnelle locale en agriculture. Economie rurale, n. 192-193, p. 115-122, jul./oct. 1989.

L'invention des pratiques dans l'agriculture. Paris: Karthala, 1996. 184 p.

GEERTZ, C. Savoir local, savoir global. Paris: PUF, 1983/ 1986.

LE GUEN, R.; RUAULT, C. La double appartenance professionnelle des agriculteurs biologiques. Réseaux de relations et évolution des qualifications, le cas de l'agriculture biologique. Dans: Pairs et experts dans l'agriculture. Revue TIP (Travaux, Idéologie, Pratique), v. 12, n. 1, p. 49-87, 1994.
LEMERY, B. Lectures sociologiques des activités de conseil technique en agriculture. Essai sur les processus de rationalisation. Lyon, 1991, 328 p. Thèse (Doctorat de Sociologie) - Université Lumière - Lyon 2. + annexes.

SARDAN, J. P. O. Anthropologie et développement. Essai en anthropologie du changement social. Paris: Apad-Karthala, 1995. $218 \mathrm{p}$.

RAGOT, M. Les producteurs laitiers face à l'éventualité d'une reconversion à l'agriculture biologique. Enquête sociologique dans le Morbihan et le Cantal. Mémoire d'ingénieur. Dijon: ITA, ENESAD/INRA - SAD, 1998. 94 p.

RUAULT, C. Relations professionnelles et élaboration des références techniques en agrobiologie. Approche sociologique de l'installation et de la reconversion. In: CONGRÈS DE L'ACAB: L'AGRICULTURE BIOLOGIQUE AUJOURD'HUI, CLÉS POUR LA RECONVERSION, 1992, [S.1.] Actes... [S.1.]: Editions Nature et Progrès, maio 1992. p. 137-150.

Conceptions et pratiques de conseil et de développement en agriculture biologique. Les cahiers du BIOGER, GEPAB Paimpont, n. 3, 106 p., 1997.

WEBER, M. Economie et société. Paris: Plon, 1971. 